GRASAS Y ACEITES 71 (3)

July-September 2020, e371

ISSN-L: 0017-3495

https://doi.org/10.3989/gya.0345191

\title{
Enhancement of lipid productivity from a promising oleaginous fungus Aspergillus sp. strain EM2018 for biodiesel production: Optimization of culture conditions and identification
}

\author{
E.M. Abdellah ${ }^{\mathrm{a}}$, T.H. Ali ${ }^{\mathrm{a}}$, D.A.M. Abdou ${ }^{\mathrm{b}}$, N.M. Hassanein ${ }^{\mathrm{b}}$, \\ M. Fadel ${ }^{\mathrm{a}}$, A.A. Karam El-Din ${ }^{\mathrm{b}}$ and D.H. El-Ghonemy ${ }^{\mathrm{a}, \bigotimes}$ \\ ${ }^{a}$ Microbial Chemistry Department, Genetic Engineering and Biotechnology Research Division, \\ National Research Centre, 33 El Buhouth St., EG-121622 Giza, Egypt. \\ ${ }^{\mathrm{b}}$ Microbiology Department, Faculty of Science, Ain Shams University, Abbaseyya, 1156 Cairo, Egypt. \\ Corresponding author: delghonamy@yahoo.com
}

Submitted: 26 March 2019; Accepted: 18 September 2019; Published online: 26 August 2020

\begin{abstract}
SUMMARY: Oleaginous fungi have recently gained increasing attention among different microorganisms due to their ability for lipid production for the preparation of biofuel. In the present study, a locally isolated fungus E45, identified genetically as Aspergillus sp. strain EM2018, was found to produce $25.2 \%$ of the total lipids content of its dry cell weight (DCW). Optimization of culture conditions was performed and lipid accumulation increased by about 2.4 fold (from $25.2 \%$ to $60.1 \%$ of $\mathrm{DCW}$ ) when the fungus was grown for seven days in the potato dextrose $(50 \mathrm{~g} / \mathrm{L})$ liquid medium at $\mathrm{pH} 5.0$, incubation temperature at $30^{\circ} \mathrm{C}$ and inoculum size of $2 \times 10^{6}$ spore $/ \mathrm{mL}$. Supplementation of the medium with yeast extract and $\mathrm{NaNO}_{3}$ at a concentration of $0.05 \%$ as organic and inorganic nitrogen sources, respectively, increased lipid production ( $53.3 \%$ lipid/dry biomass). Gas chromatography analysis of fungal lipids revealed the presence of saturated (mainly palmitic acid C16:0 $(33 \%)$ and lignoceric acid $\mathrm{C} 24: 0(15 \%))$ and unsaturated fatty acids in different proportions (mainly linoleic acid C18:2 (24.4\%), oleica cid C18:1 (14\%) and arachidonic C20:4 (7.4\%). These findings suggest this new oleaginous fungus as a promising feedstock for various industrial applications and for the preparation of biodiesel.
\end{abstract}

KEYWORDS: Aspergillus sp. strain EM2018; Biodiesel; GC analysis; Lipid production; Optimization

RESUMEN: Mejora de la producción de lípidos de un prometedor hongo oleaginoso Aspergillus sp. cepa EM2018 para la formación de biodiesel: optimización de las condiciones de cultivo e identificación. Los hongos oleaginosos recientemente están ganando una creciente atención entre diferentes microorganismos debido a sus capacidades de producción de lípidos para la preparación de biocombustibles. En el presente estudio, se descubrió que un hongo E45 aislado localmente, identificado genéticamente como la cepa Aspergillus sp. EM2018, produce un $25,2 \%$ de lípidos totales de su peso de células secas (DCW). Se realizó la optimización de las condiciones de cultivo y la acumulación de lípidos se incrementó aproximadamente 2,4 veces (del 25,2\% al 60,1\% de DCW) cuando el hongo creció durante siete días en un medio líquido de dextrosa de papa $(50 \mathrm{~g} / \mathrm{L})$ a pH $5.0,30{ }^{\circ} \mathrm{C}$ de temperatura de incubación y $2 \times 106$ esporas $/ \mathrm{ml}$ de tamaño de inóculo. La suplementación del medio con extracto de levadura y $\mathrm{NaNO}_{3}$ a una concentración de $0,05 \%$ como fuentes de nitrógeno orgánico e inorgánico, respectivamente, aumentó aún más la producción de lípidos (53,3\% de lípidos/biomasa seca). El análisis mediante cromatografía de gases de los lípidos fúngicos reveló la presencia de ácidos grasos saturados (principalmente palmítico C16:0 (33\%) y lignocérico C24:0 (15\%)) y ácidos grasos insaturados en diferentes proporciones (principalmente linoleico C18:2 (24.4\%), oleico C18:1 (14\%) y araquidónico C20:4 (7,4\%). Estos hallazgos sugieren que este nuevo hongo oleaginoso es una materia prima prometedora para diversas aplicaciones industriales y preparación de biodiésel.

PALABRAS CLAVE: Análisis de GC; Aspergillus sp. cepa EM2018; Biodiésel; Optimización; Producción de lípidos

ORCID ID: Abdellah EM https://orcid.org/0000-0002-2446-5422, Ali TH https://orcid.org/0000-0002-3106-4467, Abdou DAM https://orcid.org/0000-0002-9627-721X, Hassanein NM https://orcid.org/0000-0003-2086-4474, Fadel M https://orcid.org/0000-0002-4271-3725, Karam El-Din AA https://orcid.org/0000-0001-7165-2629, El-Ghonemy DH https://orcid.org/0000-0003-4233-5872

Citation/Cómo citar este artículo: Abdellah EM, Ali TH, Abdou DAM, Hassanein NM, Fadel M, Karam El-Din AA, El-Ghonemy DH. 2020. Enhancement of lipid productivity from a promising oleaginous fungus Aspergillus sp. strain EM2018 for biodiesel production: Optimization of culture conditions and identification. Grasas Aceites 71 (3), e371. https://doi.org/10.3989/gya.0345191

Copyright: (C2020 CSIC. This is an open-access article distributed under the terms of the Creative Commons Attribution 4.0 International (CC BY 4.0) License. 


\section{INTRODUCTION}

Renewable energy resources have triggered great attention because of the scarcity of known petroleum reserves. Biofuel takes a pivotal approach to facing the high energy prices of crude oil reserves, to reduce greenhouse gas emissions due to its favorable combustion emission profile and to enhance a sustainable economy (Ghaly et al., 2010). Biodiesel has emerged as an environmentally-friendly and renewable alternative fuel to petroleum-based fuels, which is produced by the transesterification of vegetable oils, animal fats and plant oils with low molecular weight alcohols. Conventional biodiesel is mainly produced by the chemical transesterification of the vegetable oil. However, it is competing with food production and security (Yehia et al., 2017).

All microorganisms synthesize lipids that are essential for their membranous structures; however, a few microorganisms can accumulate lipids which account for more than $20 \%$ of their dry cell weight and are called "oleaginous microorganisms". This value can be increased by up to $70 \%$ of their biomass, especially under nitrogen limitation conditions. The fatty acid profile of microbial lipid is quite similar to that of conventional vegetable oils. Hence, single cell oil (SCO) production by microorganisms has recently gained attention (Azócar et al., 2010), especially oleaginous filamentous fungi, which are suggested as a favorable feedstock for several industrial applications due to their ability to accumulate lipids, mostly in the form of triacylglycerols (TAG) (Zhao et al., 2011).

The utilization of microorganisms as a lipid source has been investigated for many applications such as in pharmaceuticals, food additives and feed ingredients for aquaculture. Microorganisms have also been used as a source of edible oils because they have the ability to produce oils rich in polyunsaturated fatty acids (PUFAs), which are in demand for infant nutrition and as dietary supplements (Vicente et al., 2010). Microorganisms can accumulate high levels of lipids using biomass residuals as a carbon source. The principal oleaginous microbial species used are microalgae, yeast, fungi and bacteria. However, oleaginous fungi are of interest owing to their high growth, no need for light energy when compared with algae, good lipid profiles for making high quality biodiesel, ability to use different carbon sources for growth and lipid production (Ruan et al., 2013), production of oils through solid state fermentation (SSF) with low capital cost and low energy demand, the fact that oil production is not subjected to seasonal weather fluctuations and their ability to accumulate large amounts of high-valued PUFAs such as arachidonic acid (AA) and $\gamma$-linolenic acid (GLA) (Chen et al., 2012). In this regard, Chuppa-Tostain et al., (2018) reported that the intracellular lipids of the biomass of A. niger grown in sugarcane distillery waste water (SDW) revealed high contents of oleic acid and good physical properties relevant for biodiesel applications.

Extensive research has been reported for PUFA production, e.g. linolenic and arachidonic acids, from oleaginous microorganisms. $\gamma$-linolenic acid (C18:3), acts as an important intermediate in the prostate gland in derivative biosynthesis and is considered an essential fatty acid for humans (Mamatha et al., 2008). Linoleic acid (C18:2) has been reported to be effective for curing or preventing several diseases, such as hyper-cholestromia, rheumatoid arthritis, atopic eczema, cardiovascular diseases and asthma. In addition, arachidonic acid (C20:4) plays a great pharmaceutical role in treating arthritis, increasinng muscle mass and overcoming depression. The enhancement of lipid accumulation by fungi requires the optimization of culture conditions during the fermentation period (Ageitos et al., 2011). Therefore, the aims of the present study were to find a new fungal isolate with high lipid production and to study the effects of different physiological conditions to maximize oil production for biodiesel production and for various applications.

\section{MATERIALS AND METHODS}

\subsection{Chemicals}

Potato dextrose liquid (PDL) and potato dextrose agar (PDA) media were purchased from Liofilchem Bacteriology products (Italy). Vanillin was purchased from SD Fine Chem Limited (Mumbai, India). The chemicals and organic solvents used throughout the work were purchased from Sigma-Aldrich (St. Louis, MO, USA). Olive oil was bought from a local hypermarket (Cairo, Egypt).

\subsection{Isolation of microorganisms and maintenance}

In this study, fifty fungal strains were locally isolated from different soil samples (Mit Ghamr, El-Dakahleya, Egypt) using a serial dilution plate technique. Briefly, one gram of each soil sample was aseptically transferred to a flask containing $99 \mathrm{~mL}$ of sterile distilled water and then shaken (Innova ${ }^{\circledR} 4230$ shaker incubator; New Brunswick Scientific) at $100 \mathrm{rpm}$ for $10 \mathrm{~min}$ and the dilution procedure was performed to give up to $10^{-6}$ dilutions. With the help of a sterile micropipette, 0.1 $\mathrm{mL}$ of each diluted sample was transferred onto a PDA medium containing $5 \mathrm{mg} / \mathrm{L}$ of streptomycin, $\mathrm{pH} 5.0$ and incubated at $30{ }^{\circ} \mathrm{C}$ for $72 \mathrm{~h}$. The distinct and separate colonies observed were 
collected, subcultured on PDA slant medium for 7 days at $30^{\circ} \mathrm{C}$ and finally stored at $4{ }^{\circ} \mathrm{C}$.

\subsection{Detection of aflatoxins}

Aflatoxin test for the selected strain was performed by using the High Performance Liquid Chromatography (HPLC) technique according to the Association of Official Analytical Chemist (AOAC, 2000) as follows: Two hundred $\mathrm{mL}$ of hexane were added to the cleanup dry films of the standard and test samples followed by adding $50 \mathrm{~mL}$ of trifluoroacetic acid (TFA) and mixing vigorously in the vortex mixer for $30 \mathrm{sec}$. The mixture was left to stand for $5 \mathrm{~min}$, then water-acetonitrile $(9+1 \mathrm{v} / \mathrm{v})$ was pipetted into the mixture and mixed well for $30 \mathrm{sec}$, and the mixture was left to stand for $10 \mathrm{~min}$ to form two separate layers. The lower aqueous layer was used for the HPLC analysis. The mobile phase included water:acetonitrile:methanol in a ratio of 240:120:40. The separation system was performed at an ambient temperature at a flow rate of $1.0 \mathrm{~mL} / \mathrm{min}$, the injection volume was $20 \mathrm{~L}$ for both the standard solutions and tested samples. The fluorescence detector was operated at a wavelength of $360 \mathrm{~nm}$ for excision and $440 \mathrm{~nm}$ for emission. The data were reported using Millennium Chromatography and Manager Software breeze 2 .

\subsection{Morphological characterization}

The morphological (color, texture appearance, and diameter of the colonies) and microscopic characteristics of the fungal isolate E45 (microscopic slide examination of spores and mycelia) were determined by Regional Center for Mycology and Biotechnology, El-Azhar University, Cairo, Egypt.

\subsection{S-rRNA gene sequencing and phylogenetic tree}

The selected oleaginous fungus was identified genetically based on the 18S-rRNA sequences of their internal transcribed spacer (ITS) regions. Fungal isolate DNA was extracted by the protocol of Umesha et al., (2016). Briefly, mycelia were harvested by filtration from a liquid culture after two days of incubation and were ground into a fine powder in a sterile mortar using liquid nitrogen. An Ezup column fungi genomic DNA purification kit (Accu 107 Prep PCR DNA purification kit, k-30341, Bioneer Corporation) was used for genomic DNA extraction. The ITS region was amplified using the universal primers ITS1 (5'-TCCGTAGGTGAACCTGCGG-3') and ITS4 (5'-TCCTCCGCTTATTGATATGC-3').
Polymerase chain reaction (PCR) amplification was performed with an initial denaturation at $95^{\circ} \mathrm{C}$ for $3 \mathrm{~min}$ followed by 30 cycles of $95^{\circ} \mathrm{C}$ for $1 \mathrm{~min}$, beginning at $55^{\circ} \mathrm{C}$ for $30 \mathrm{~s}$ and extending to $72{ }^{\circ} \mathrm{C}$ for $1 \mathrm{~min}$, with a final extension at $72^{\circ} \mathrm{C}$ for $10 \mathrm{~min}$. PCR fragments were purified using a SanPrep column DNA gel extraction kit (Sangon Biotech). The obtained sequences were BLASTsearched to find matches within the National Center for Biotechnology Information (NCBI) database. Closely related multiple sequences were aligned and corrected. The phylogenetic tree was constructed using the neighbor-joining program in MEGA 5.0 (Tamura et al., 2007).

\subsection{Determination of mycelial dry weight and extraction of fungal lipids}

The selected fungus was inoculated in a sterilized PDL medium (pH 5.0) and incubated at $30{ }^{\circ} \mathrm{C}$ for 7 days in static conditions. After the fermentation period, the fungal mats were harvested by filtration (Whatman No.1), rinsed thoroughly with sterile distilled wáter and dried in a hot air oven $\left(55^{\circ} \mathrm{C}\right)$ until reaching a constant weight. The fungal growth was determined gravimetrically and expressed as the dry weight of biomass per liter of the culture medium (Devi et al., 2009).

Lipids were extracted by using six different solvent mixtures including chloroform: methanol $(\mathrm{C}$ : M) (2:1), soxhlet extraction using hexane: isopropanol (3:2), methanol: chloroform: $\mathrm{H}_{2} \mathrm{O}$ (2:1:0.8), dichloromethane: methanol (9:1), and hexane: acetone (1:1) (Halim et al., 2012).

\subsection{Lipid determination}

The colorimetric sulfo-phospho-vanillin (SPV) is a rapid method which is employed for the direct quantitative measurement of lipids (Inouye and Lotufo, 2006). SPV reagent was freshly prepared by dissolving $0.6 \mathrm{~g}$ vanillin in $10 \mathrm{~mL}$ absolute ethanol; $90 \mathrm{~mL}$ of deionized water were added and the mixture was stirred continuously, then $400 \mathrm{~mL}$ of concentrated phosphoric acid was added and the mixture was stored in the dark until use. For lipid quantification, two $\mathrm{mL}$ of concentrated sulfuric acid $(98 \%)$ were added to the extracted sample $(0.1 \mathrm{~mL})$ and placed in a boiling water bath at $100{ }^{\circ} \mathrm{C}$, then cooled for $5 \mathrm{~min}$ in an ice bath. Five $\mathrm{mL}$ of SPV reagent were added and the sample was incubated for $15 \mathrm{~min}$ in an incubator shaker at $200 \mathrm{rpm}$. The SPV reacted with lipids to produce a distinct pink color, and the intensity was quantified at $530 \mathrm{~nm}$ (Cary-100 UV-Vis-Spectrophotometer, Agilent Technologies, Germany). A standard curve was prepared with different concentrations of olive oil (Mishra et al., 2014). 


\subsection{Optimization of physiological and nutritional parameters}

\subsubsection{Effect of media composition}

Eight fermentation media were used to evaluate the ability of the selected fungus for lipid accumulation in submerged fermentation. The media used was named as follow:

I) commercial Potato-Dextrose Liquid (PDL) medium (control),

II) Czapek Dox's medium (dextrose; 20, $\mathrm{NaNO}_{3}$; 2, $\left.\mathrm{KH}_{2} \mathrm{PO}_{4} ; 1, \mathrm{MgSO}_{4} ; 0.5, \mathrm{KCl} ; 0.5 \mathrm{~g} / \mathrm{L}\right)$,

III) Sabaroud medium (dextrose; 40, peptone; $10 \mathrm{~g} / \mathrm{L})$,

IV) Potato-Dextrose Yeast Extract medium (potatoes; 300, dextrose; 20, yeast; $5 \mathrm{~g} / \mathrm{L}$ ),

V) Yeast Extract Malt broth (yeast extract; 4, malt extract; 10, dextrose; $4 \mathrm{~g} / \mathrm{L})$,

VI) Yeast Peptone Dextrose (peptone; 20, yeast; 10, dextrose; 20, $\mathrm{NH}_{4} \mathrm{Cl} ; 4, \mathrm{KH}_{2} \mathrm{PO}_{4} ; 0.5, \mathrm{MgCl}_{2}$; $1 \mathrm{~g} / \mathrm{L})$,

VII) Prepared Potato Dextrose liquid medium (potatoes; 300, dextrose; $20 \mathrm{~g} / \mathrm{L}$ ),

VIII) Basal medium ( $\left(\mathrm{NH}_{4}\right)_{2} \mathrm{SO}_{4} ; 0.5, \mathrm{KH}_{2} \mathrm{PO}_{4} ; 7$, $\mathrm{Na}_{2} \mathrm{HPO}_{4} ; 2, \quad \mathrm{MgSO}_{4} .7 \mathrm{H}_{2} \mathrm{O} ; 1.5, \mathrm{CaCl}_{2} 2 \mathrm{H}_{2} \mathrm{O}$; $0.1, \mathrm{FeCl}_{3} \cdot 6 \mathrm{H}_{2} \mathrm{O} ; 0.008, \mathrm{ZnSO}_{4} \cdot 7 \mathrm{H}_{2} \mathrm{O} ; 0.001$, $\mathrm{CuSO}_{4} .5 \mathrm{H}_{2} \mathrm{O} ; 0.0001, \mathrm{CO}\left(\mathrm{NO}_{3}\right)_{2} .2 \mathrm{H}_{2} \mathrm{O} ; 0.0001$, $\mathrm{MnSO}_{4} .5 \mathrm{H}_{2} \mathrm{O} ; 0.0001$, yeast extract; 0.5 , dextrose; 30, xylose; $30 \mathrm{~g} / \mathrm{L})$.

All media were adjusted before autoclaving (at $121{ }^{\circ} \mathrm{C}$ for $15 \mathrm{~min}$ ) at $\mathrm{pH} 6.0$. The flasks were inoculated and incubated for seven days at $30^{\circ} \mathrm{C}$.

\subsubsection{Comparison between static and shaking conditions}

A comparable study between static and shaking conditions $(150 \mathrm{rpm})$ was carried out to study the effect of shaking on lipid production by the fungal isolate when grown for seven days at $30{ }^{\circ} \mathrm{C}$ in $250 \mathrm{~mL}$ Erlenmeyer flasks containing $50 \mathrm{~mL}$ of a sterile prepared PDL medium of $\mathrm{pH} 6.0$.

\subsubsection{Effect of medium $\mathrm{pH}$, incubation period and temperature on lipid production}

The influence of the initial medium $\mathrm{pH}$ on lipid accumulation by the selected fungal isolate was investigated by changing the $\mathrm{pH}$ value of the medium from 3.0 to 9.0 before autoclaving using $1 \mathrm{~N} \mathrm{HCl}$ or $1 \mathrm{~N} \mathrm{NaOH}$. The growth pattern, biomass and oil production by the fungus were evaluated by incubating the inoculated production media (prepared PDL medium) up to 9 days and lipid accumulation was determined every $24 \mathrm{~h}$ interval. The optimum incubation temperature for the optimal lipid yields by the fungal isolate was studied by varying the temperature from 25 to $45^{\circ} \mathrm{C}$.

\subsubsection{Aeration and inoculum size}

Two $\mathrm{mL}$ aliquots of inoculum size $2 \times$ $10^{6}$ spores $/ \mathrm{mL}$ were used to inoculate $250 \mathrm{~mL}$ Erlenmeyer flasks containing different volumes $(25,50,75,100,125,150 \mathrm{~mL})$ of prepared PDL médium ( $\mathrm{pH}$ 5.0). The inoculated flasks were incubated statically at $30{ }^{\circ} \mathrm{C}$ for 7 days then the fungal biomass was harvested for lipid estimation. The optimum inoculum size for lipid production was studied as follows: different inoculum concentrations ranging from $2 \times 10^{2}$ to $2 \times 10^{7}$ spores $/ \mathrm{mL}$ were prepared from the 7-day-old PDA slant, and $100 \mu \mathrm{L}$ of each concentration were spread over the surface of PDA-containing plates by the use of a sterile glass spreading rod. All plates were incubated at $30{ }^{\circ} \mathrm{C}$ for $48 \mathrm{~h}$ and the number of fungal colonies was caculated.

An aliquot of $1 \mathrm{~mL}(\mathrm{v} / \mathrm{v})$ of each inoculum concentration was used to inoculate $250-\mathrm{mL}$ Erlenmeyer flasks, each containing $50 \mathrm{~mL}$ of PDL medium adjusted at $\mathrm{pH} 6.0$ before autoclaving (at $121{ }^{\circ} \mathrm{C}$ for $20 \mathrm{~min}$ ). The inoculated flasks were incubated for seven days at $30{ }^{\circ} \mathrm{C}$ in a static condition.

The colony forming unit (CFU) was calculated using the formula:

$\mathrm{CFU} / \mathrm{mL}=$ no. of colonies counted on the plate $\times$ the reciprocal of the dilution factor.

\subsubsection{Influence of supplementary carbon and nitrogen sources and their concentrations}

To study the impact of supplementing different carbon sources on fungal growth and lipid accumulation by the selected fungal isolate, the production medium (PDL) was amended with ten carbon sources (dextrose, fructose, starch, mannose, raffinose, lactose, xylose, galactose, sucrose and maltose); each was added individually at equal molar amounts of carbon. The effect of varying concentrations $(1-8 \%)$ of the selected carbon source (dextrose) on growth and lipid production was investigated. Similarly, organic (yeast extract, beef ex., malt ex. and peptone) and inorganic (sodium nitrate, ammonium chloride, ammonium sulfate and ammonium oxalate) nitrogen sources were supplemented individually $(0.5 \mathrm{~g} / \mathrm{L})$ as additives to the PDL medium to study their effects on fungal lipid production.

\subsubsection{Influence of metal ions on fungal lipid production}

Fifty $\mathrm{mg}$ of each metal ion $\left(\mathrm{Ca}^{+2}, \mathrm{Fe}^{+3}, \mathrm{Mg}^{+2}\right.$, $\mathrm{Mn}^{+2}, \mathrm{Zn}^{+2}$ and $\mathrm{Cu}^{+2}$ ) were added individually to $50 \mathrm{~mL}$ of PDL medium in 250-mL Erlenmeyer flasks to investigate its effect on fungal growth and lipid production. 


\subsection{Fatty acid methyl ester preparation}

The fatty acids in the fungal lipid sample were converted to fatty acid methyl esters using acid catalyzed transesterification. Briefly, a sample of $0.5 \mathrm{~mL}$ was dissolved in $1 \mathrm{~mL}$ of toluene in a flask fitted to a condenser, then sulfuric acid $(1 \%)$ in methanol $(2.0 \mathrm{~mL})$ was added and the mixture was refluxed for $7 \mathrm{~h}$ at $50{ }^{\circ} \mathrm{C}$. $5 \mathrm{~mL}$ of $5 \% \mathrm{NaCl}$ was added and the required esters were extracted with hexane $(2 \mathrm{~mL}$ hexane for each $5 \mathrm{~mL}$ of the previous mixture). The hexane layer was washed with distilled water (double the sample volume) containing 2\% potassium bicarbonate. The layers were separated using a separating funnel and the esters were dried over anhydrous sodium sulfate. The obtained solution was then filtered to remove the drying agent and the solvent was removed using a rotary evaporator under reduced pressure. Finally, the sample was analyzed by GC.

\subsection{Gas chromatographic analysis}

The fatty acid profile of the fungal lipid was determined from the peak areas of the gas chromatogram (GC) using standards for calibration. The GC analysis for FAMEs was performed using Agilent Technologies $6890 \mathrm{~N}$ (Net Work GC system) USA. Supelco 37 component FAMEs mix. (cat. no. 1 AMP) was used as a standard. The oven was held at an initial temperature of $50{ }^{\circ} \mathrm{C}$ for two min at the rate of $10,8,5$, and $6{ }^{\circ} \mathrm{C} / \mathrm{min}$, then increased to $70,170,200$ and $240^{\circ} \mathrm{C}$, at the rate of $2,9,5,10 \mathrm{~min}$ with a run time of $55 \mathrm{~min}$. The injector temperature was held at $250{ }^{\circ} \mathrm{C}$ splitless. The temperature of the flame ionization detector (FID) was $280{ }^{\circ} \mathrm{C}$ with a flow rate of $1.5 \mathrm{~mL} / \mathrm{min}$. The capillary column HP-5MS (5\% phenyl methylsiloxane) had dimensions of diameter $320 \mu \mathrm{m}$, length of $30 \mathrm{~m}$ and film thickness of $0.25 \mu \mathrm{m}$. Nitrogen was the carrier gas at a flow rate of $30 \mathrm{~mL} / \mathrm{min}$, while the hydrogen and air flow rates were 30 and 300 $\mathrm{mL} / \mathrm{min}$, respectively.

\subsection{Statistical analysis}

All experiments were performed in triplicate and error bars denote the standard deviation.

\section{RESULTS AND DISCUSSION}

\subsection{Screening of locally isolated filamentous fungi for their lipid production}

Among the fifty fungal isolates grown on PDL media for 7 days at $30{ }^{\circ} \mathrm{C}$, the growth pattern of isolate $\mathrm{E} 45$ was the best and gave the highest lipid yield. This fungal strain had the ability to accumulate $25.2 \%$ lipids of its dry biomass weight followed by isolates E23, E10 and E9 which accumulated 24.3, 23.1 and $21.6 \%$ lipids of dry biomass, respectively (Table 1). The lowest amount of lipid accumulation (3\% of its dry biomass weight) was detected in the cells of the fungal isolate $\mathrm{E} 31$.

\subsection{Aflatoxins detection}

A toxicity test was performed according to AOAC (2000) to confirm the selection of the highest lipid producing fungal isolate. The results clearly indicated that the fungal strain E45 was a non-mycotoxins producing fungus as indicated in Figure 1 (A and B).

\subsection{Microscopic and molecular identification of the fungal isolate $\mathbf{E 4 5}$}

Fungal taxonomy is based on a comparative study among morphological features. In this study, the microscopic examination of the selected fungal isolate E45 showed spherical conidia of diameter $3.0 \mu \mathrm{m}$ with radiated conidial heads and the conidiophores were $9.0 \mu \mathrm{m}$ in diameter (Figure 2). PCR amplification of the 18S rRNA gene, using the primers ITS1 and ITS4, was also performed to confirm the identity of the selected fungal isolate. The phylogenetic analysis suggests that isolate E45 is a new Aspergillus species and the nucleotide sequences of $18 \mathrm{~S}$ rRNA genes were deposited to GenBank under the accession number MK377325 (Figure 3).

\subsection{Optimization of physiological conditions for maximum lipid production}

\subsubsection{Effect of media composition on lipid accumulation}

Media composition is considered an important factor which has an effect on growth and lipid production by microorganisms. A comparative study was performed on different media to determine the effect of medium composition on biomass and lipid production by the Aspergillus sp. strain EM2018. The results revealed that the prepared potato dextrose liquid medium (medium VII) was the best for biomass and lipid production (5 g lipid/L; 31.6\% lipid/dry biomass) followed by medium VIII (4.4 g lipid/L; 29.3\% lipid/dry biomass); while the lowest lipid content of $0.5 \mathrm{~g}$ lipid/L (8.6\% lipid/dry biomass) was observed in medium V, as shown in Fig. 4. Similarly, Ali and El-Ghonemy (2014) reported that the highest biomass and lipid production by Trichoderma viride NRC 314 were observed in the PDL medium. Therefore, medium VII was used in all the subsequent studies. 
TABLE 1. Screening of different fungal isolates for their lipid production

\begin{tabular}{|c|c|c|c|c|c|c|c|}
\hline Isolate No. & $\begin{array}{c}\text { Dry } \\
\text { biomass }(\mathrm{g} / \mathrm{L})\end{array}$ & $\begin{array}{l}\text { Lipid content } \\
(\mathrm{g} / \mathrm{L})\end{array}$ & $\begin{array}{c}\text { Lipid/ dry } \\
\text { biomass (\%) }\end{array}$ & Isolate No. & $\begin{array}{c}\text { Dry } \\
\text { biomass }(g / L)\end{array}$ & $\begin{array}{l}\text { Lipid content } \\
(\mathrm{g} / \mathrm{L})\end{array}$ & $\begin{array}{c}\text { Lipid/ dry } \\
\text { biomass (\%) }\end{array}$ \\
\hline E1 & $5.0 \pm 0.1$ & $0.32 \pm 0.02$ & $6.4 \pm 0.1$ & E26 & $6.0 \pm 0.3$ & $1.00 \pm 0.05$ & $16.6 \pm 0.4$ \\
\hline E2 & $4.0 \pm 0.1$ & $0.16 \pm 0.01$ & $4.0 \pm 0.1$ & E27 & $4.0 \pm 0.2$ & $0.40 \pm 0.03$ & $10.0 \pm 0.3$ \\
\hline E3 & $5.8 \pm 0.3$ & $0.50 \pm 0.02$ & $8.6 \pm 0.1$ & E28 & $2.2 \pm 0.1$ & $0.12 \pm 0.02$ & $5.5 \pm 0.2$ \\
\hline E4 & $6.6 \pm 0.2$ & $0.80 \pm 0.04$ & $12.1 \pm 0.3$ & E29 & $6.6 \pm 0.3$ & $0.68 \pm 0.03$ & $10.3 \pm 0.2$ \\
\hline E5 & $6.0 \pm 0.1$ & $0.48 \pm 0.03$ & $8.0 \pm 0.3$ & E30 & $2.8 \pm 0.1$ & $0.20 \pm 0.01$ & $7.1 \pm 0.2$ \\
\hline E6 & $5.8 \pm 0.4$ & $0.50 \pm 0.02$ & $8.6 \pm 0.2$ & E31 & $2.0 \pm 0.1$ & $0.06 \pm 0.00$ & $3.0 \pm 0.1$ \\
\hline E7 & $8.0 \pm 0.2$ & $0.96 \pm 0.07$ & $12.0 \pm 0.3$ & E32 & $5.6 \pm 0.3$ & $0.54 \pm 0.03$ & $9.6 \pm 0.2$ \\
\hline E8 & $6.4 \pm 0.1$ & $0.62 \pm 0.02$ & $9.6 \pm 0.2$ & E33 & $3.4 \pm 0.2$ & $0.16 \pm 0.01$ & $4.7 \pm 0.1$ \\
\hline E9 & $13.0 \pm 0.4$ & $2.82 \pm 0.06$ & $21.6 \pm 0.6$ & E34 & $11.0 \pm 0.4$ & $2.08 \pm 0.04$ & $18.9 \pm 0.4$ \\
\hline E10 & $10.8 \pm 0.3$ & $2.50 \pm 0.05$ & $23.1 \pm 0.6$ & E35 & $7.0 \pm 0.2$ & $0.80 \pm 0.03$ & $11.4 \pm 0.4$ \\
\hline E11 & $13.2 \pm 0.2$ & $2.68 \pm 0.07$ & $20.3 \pm 0.5$ & E36 & $1.8 \pm 0.1$ & $0.06 \pm 0.00$ & $3.3 \pm 0.1$ \\
\hline E12 & $4.6 \pm 0.1$ & $0.52 \pm 0.02$ & $11.3 \pm 0.2$ & E37 & $5.6 \pm 0.4$ & $0.54 \pm 0.02$ & $9.6 \pm 0.2$ \\
\hline E13 & $10.4 \pm 0.3$ & $1.98 \pm 0.01$ & $19.0 \pm 0.3$ & E38 & $10.8 \pm 0.2$ & $1.72 \pm 0.04$ & $15.9 \pm 0.3$ \\
\hline E14 & $6.0 \pm 0.4$ & $0.62 \pm 0.03$ & $10.3 \pm 0.2$ & E39 & $6.6 \pm 0.1$ & $0.90 \pm 0.05$ & $13.6 \pm 0.3$ \\
\hline E15 & $6.4 \pm 0.4$ & $1.16 \pm 0.04$ & $18.1 \pm 0.6$ & $\mathrm{E} 40$ & $2.0 \pm 0.1$ & $0.14 \pm 0.03$ & $7.0 \pm 0.1$ \\
\hline E16 & $8.8 \pm 0.1$ & $1.28 \pm 0.02$ & $14.5 \pm 0.5$ & E41 & $6.0 \pm 0.3$ & $0.68 \pm 0.04$ & $11.3 \pm 0.2$ \\
\hline E17 & $4.4 \pm 0.3$ & $0.52 \pm 0.03$ & $11.8 \pm 0.4$ & E42 & $9.0 \pm 0.1$ & $1.38 \pm 0.05$ & $15.3 \pm 0.3$ \\
\hline E18 & $2.0 \pm 0.1$ & $0.02 \pm 0.00$ & $1.0 \pm 0.0$ & E43 & $4.4 \pm 0.2$ & $0.48 \pm 0.02$ & $10.9 \pm 0.4$ \\
\hline E19 & $5.0 \pm 0.1$ & $0.64 \pm 0.05$ & $12.8 \pm 0.5$ & E44 & $6.0 \pm 0.3$ & $0.56 \pm 0.04$ & $9.3 \pm 0.1$ \\
\hline E20 & $10.0 \pm 0.3$ & $2.14 \pm 0.07$ & $21.4 \pm 0.5$ & E45 & $\mathbf{1 5 . 0} \pm 0.4$ & $3.78 \pm 0.11$ & $\mathbf{2 5 . 2} \pm 0.6$ \\
\hline E21 & $3.0 \pm 0.1$ & $0.26 \pm 0.01$ & $8.6 \pm 0.3$ & E46 & $7.2 \pm 0.2$ & $0.88 \pm 0.05$ & $12.2 \pm 0.2$ \\
\hline E22 & $6.2 \pm 0.4$ & $0.56 \pm 0.04$ & $9.03 \pm 0.3$ & E47 & $3.8 \pm 0.1$ & $0.38 \pm 0.04$ & $10.0 \pm 0.3$ \\
\hline E23 & $13.0 \pm 0.2$ & $3.16 \pm 0.09$ & $24.3 \pm 0.5$ & E48 & $9.0 \pm 0.2$ & $1.44 \pm 0.03$ & $16.0 \pm 0.4$ \\
\hline E24 & $4.4 \pm 0.3$ & $0.32 \pm 0.02$ & $7.3 \pm 0.1$ & E49 & $5.4 \pm 0.1$ & $0.68 \pm 0.02$ & $12.5 \pm 0.1$ \\
\hline E25 & $3.0 \pm 0.1$ & $0.24 \pm 0.01$ & $8.0 \pm 0.3$ & E50 & $6.6 \pm 0.4$ & $1.00 \pm 0.04$ & $15.1 \pm 0.2$ \\
\hline
\end{tabular}

Data are expressed as mean value \pm SD of triplicate measurements. The fungal isolate with the highest lipid production is shown in bold.

\subsubsection{Comparative evaluation of static and shaking conditions}

A comparative study between static and shaking (150 rpm) culture conditions revealed that the levels of biomass and lipid accumulation of $6 \mathrm{~g} / \mathrm{L}$ and $32.7 \%$ lipid/dry biomass, respectively, by Aspergillus sp. strain EM2018 were higher in static conditions when compared with shaking conditions $(4.5 \mathrm{~g} / \mathrm{L}$; $27.6 \%$ lipid/dry biomass) after seven days of incubation at $30{ }^{\circ} \mathrm{C}$ using the prepared PDL medium (M VII) at pH 6.0, as shown in Fig. 5. These results might be due to the aeration level which proved to be an important factor for growth and lipid accumulation by microorganisms (Kirrolia et al., 2013). The amount of dissolved oxygen in the culture can greatly affect the fatty acid composition in the fungal lipids. Under static conditions, the glyceride fraction changed considerably and the amounts of phospholipids and sterols were reduced, which resulted in an increase in the amounts of saturated fatty acids (the main component of lipids). Similar results have been reported for lipid accumulation in Penicillium commune NRC 2016 when grown under a static culture condition (Hussein et al., 2017). Likewise, Kirrolia et al., (2013) reported lipid accumulations of 18.3 and $13.8 \%$ lipid/dry biomass, in the cells of Chlorococcum sp., when grown under static and shaking culture conditions, respectively.

\subsubsection{Effect of $\mathrm{pH}$, incubation period and temperature on lipid production}

Among the physical factors examined, the $\mathrm{pH}$ of the growth medium showed a great effect on biomass formation and lipid accumulation. Oleaginous microbes have various optimal $\mathrm{pH}$ values for oil production and accumulation. In general, mold can grow optimally at a $\mathrm{pH}$ slightly acidic to neutral. The data revealed that $\mathrm{pH} 5.0$ was the most suitable 
$A_{60.00}$

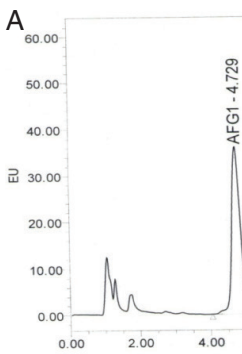

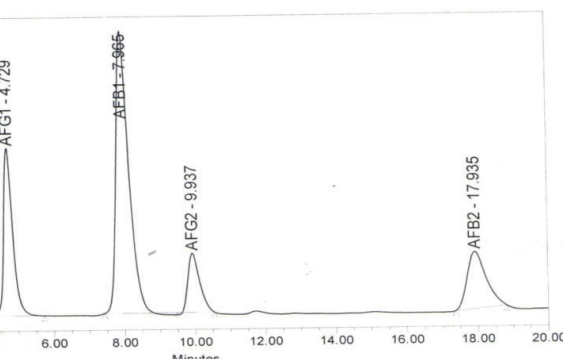

B

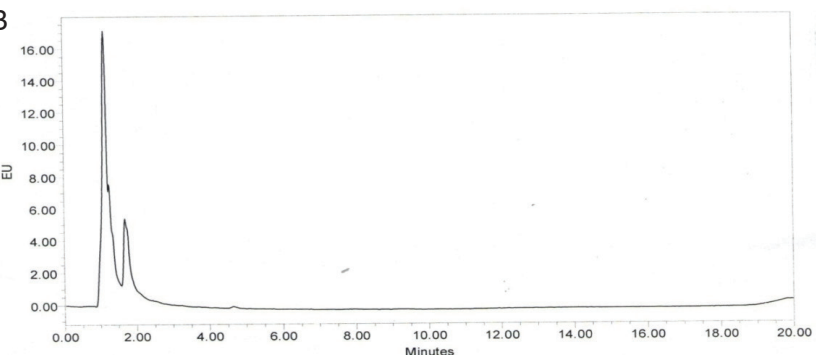

Figure 1. (A) Standard curve of aflatoxins. (B) Aflatoxin test for the oleaginous fungus Aspergillus sp. strain EM2018 using HPLC technique.

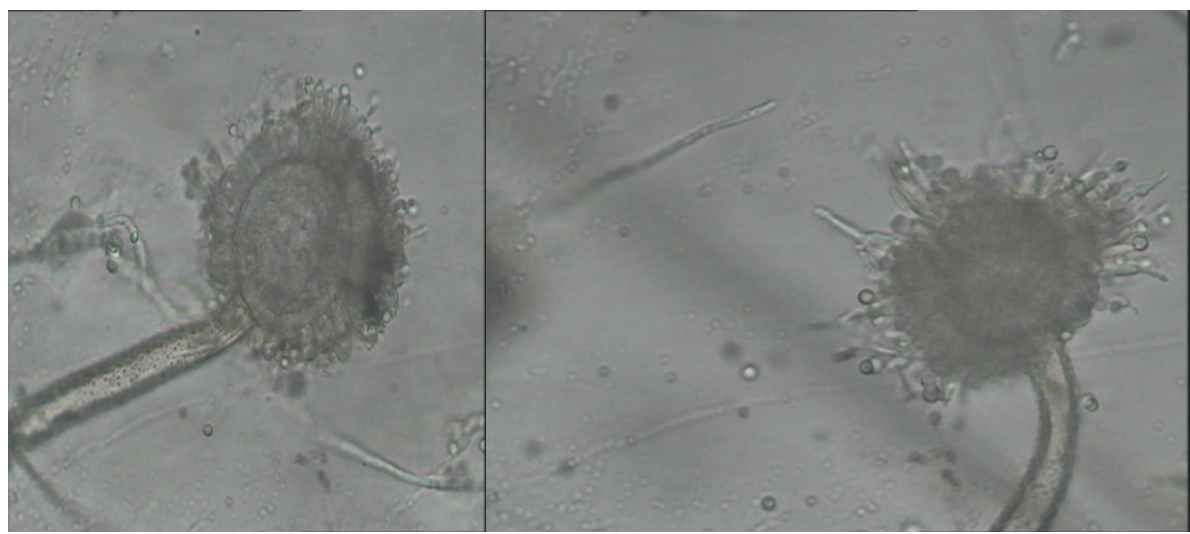

FIGURE 2. Microscopic examination of a new terrestrial fungus Aspergillus sp. strain EM2018 (GenBank accession no. MK377325): Conidiophores were $9.0 \mu \mathrm{m}$ in diameter and the conidia spherical $(3.0 \mu \mathrm{m})$ with radiated conidial heads. The vesicles globose $(26.0 \mu \mathrm{m})$.

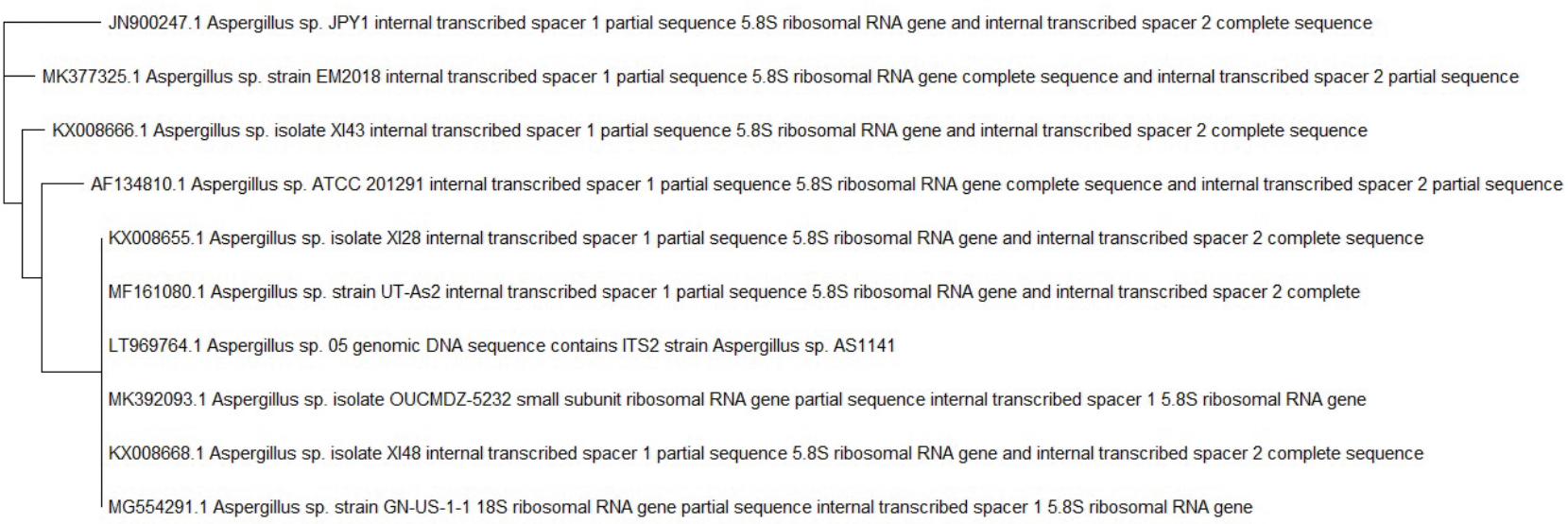

100

FIGURE 3. Phylogenetic analysis of the Aspergillus sp. strain EM2018 based on the results of PCR amplification of the 18S-rRNA gene.

for a lipid production of $33.4 \%$ lipid/dry biomass. In addition, there was a drastic reduction in the production of lipids when the Aspergillus sp. strain EM2018 was grown in extreme acidic and basic conditions, as shown in Table 2. Similarly, Abdelhamid (2018) reported a maximum lipid accumulation of $64.59 \%$ lipid/dry biomass from Fusarium oxysporum NRC 2017 at medium pH 5. Likewise, Ali et al., (2017) reported that the $\mathrm{pH}$ medium of 5.0 was optimal for lipid production by Penicillium brevicompactum 


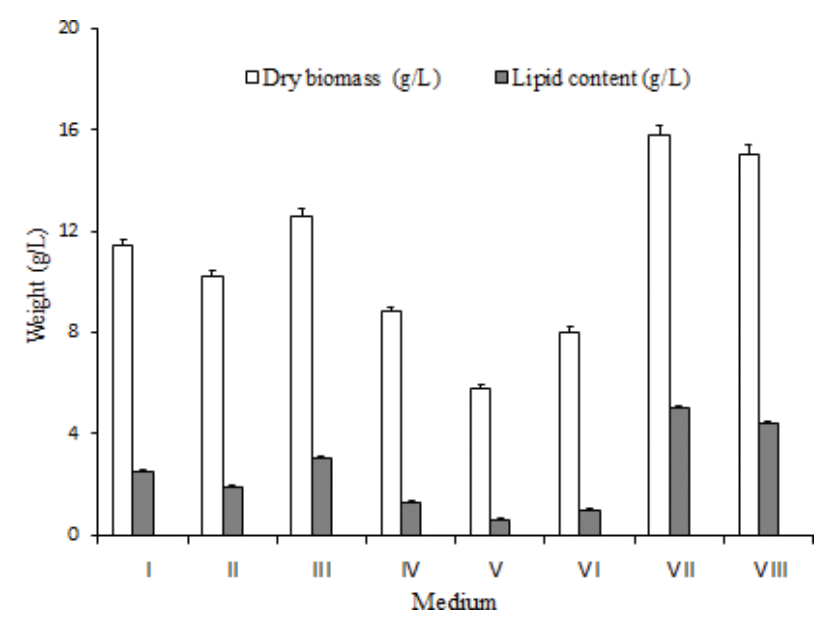

FIGURE 4. Effect of medium composition on lipid production by the Aspergillus sp. strain EM2018 (at initial $\mathrm{pH}$ of 6 , incubation temperature at $30^{\circ} \mathrm{C}$ and 7 days of incubation. Data are expressed as mean value of triplicate measurements and error bars denote the standard deviation).

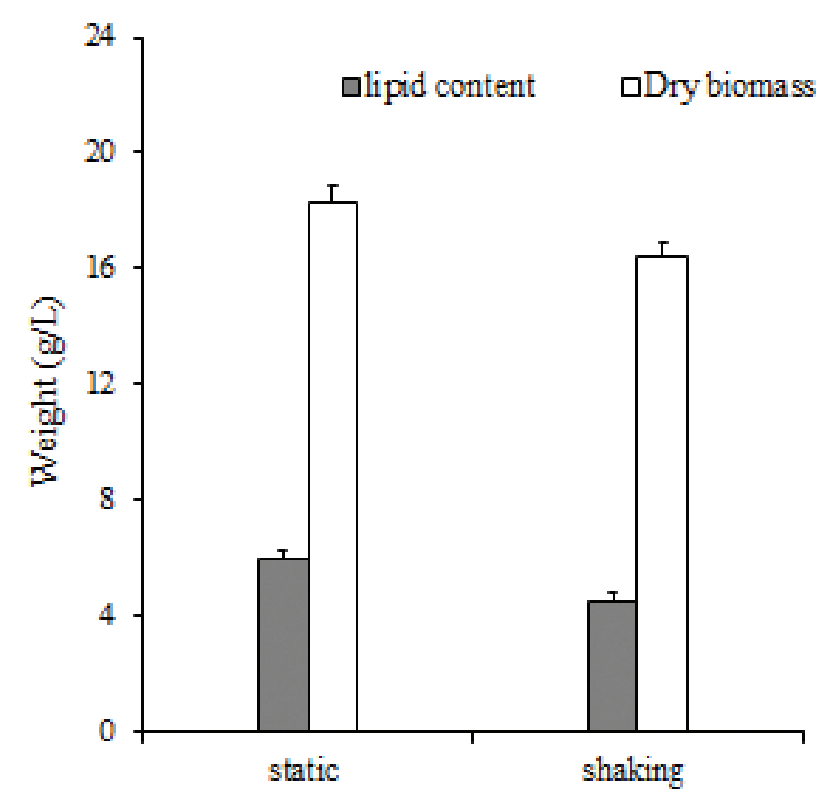

Incubation conditions

FIGURE 5. Comparison between static and shaking (150 rpm) conditions for maximum lipid production by the Aspergillus sp. strain EM2018 (at initial pH of 6, incubation temperature at $30^{\circ} \mathrm{C}$ and 7 days of incubation. Data are expressed as mean value of triplicate measurements and error bars denote the standard deviation).

NRC 829. In addition, this result is relatively close to the optimum $\mathrm{pH}$ of 5.5 for lipid accumulation by Aspergillus awamori (Venkata and Venkata 2014). Complex physiological parameters such as cell morphology and membrane permeability can be determined by the $\mathrm{pH}$ of the growth medium, as any variation in the $\mathrm{pH}$ of broth medium will greatly affect the membrane osmosis to absorb or move certain ions in the surrounding medium.

The impact of incubation period on biomass and lipid accumulation by the Aspergillus sp. strain EM2018 was evaluated. Data presented in Table 2 showe that the optimal lipid production of $37.7 \%$ lipid/dry biomass was achieved after seven days of fermentation in the prepared PDL medium (medium VII) and began to decrease by increasing the incubation time. The log phase of the strain extended from $72 \mathrm{~h}$ to $168 \mathrm{~h}$ of incubation. However, the highest biomass and lipid production were exhibited with $168 \mathrm{~h}$ old culture exhibited high lipid production. These results are in agreement with Venkata and Venkata (2014), who found that a shorter fermentation period affected the utilization of substrate by Aspergillus awamor, leading to a reduction in biomass and lipid contents. However, the highest biomass and lipid accumulation by $R$. toruloides, Aspergillus sp. and $T$. viride were reported on the fifth day of incubation (Kumar and Banerjee 2013). On the other hand, Abelhamid (2018) reported that the highest lipid production of $55.2 \%$ lipid/dry biomass by Fusarium oxysporum was obtained on the $9^{\text {th }}$ day of incubation.

Incubation temperature strongly affected biomass formation and lipid synthesis by different microorganisms. The results reported in Table 2 showed that there was an increase in fungal biomass and lipid production in the temperatures ranging from 25 to $35{ }^{\circ} \mathrm{C}$; however, the highest level of lipid accumulation of $40.7 \%$ lipid/dry biomass was reported at $30^{\circ} \mathrm{C}$. While at higher/lower temperatures compared to the optimal temperature a reduction in biomass and lipid accumulation was reported (Table 2). Different microorganisms are reported to produce PUFAs at low temperatures to maintain cell membrane fluidity. Our results are in agreement with those reported by Abdelhamid (2018) who found that the highest lipid production by Fusarium oxysporum NRC 2017 was at $30^{\circ} \mathrm{C}$. These results are in accordance with Venkata and Venkata (2014) who reported that many fungi have an optimum growth temperature at $30^{\circ} \mathrm{C}$ as they are naturally exposed to a fluctuation in temperature according to seasonal variations.

\subsubsection{Effect of aeration on lipid production by Aspergillus sp. strain EM2018}

Aeration is an important factor affecting fungal growth and lipid production. In the present study, different volumes of the medium were tested and the flask containing $50 \mathrm{~mL}$ of the prepared PDL medium (medium VII) gave the highest biomass and lipid accumulation of $16.4 \mathrm{~g} / \mathrm{L}$ and $40.8 \%$ lipid/ dry biomass, respectively, as shown in Table 2 . The amount of oxygen dissolved in the growth medium could highly affect the composition of fatty acids. 


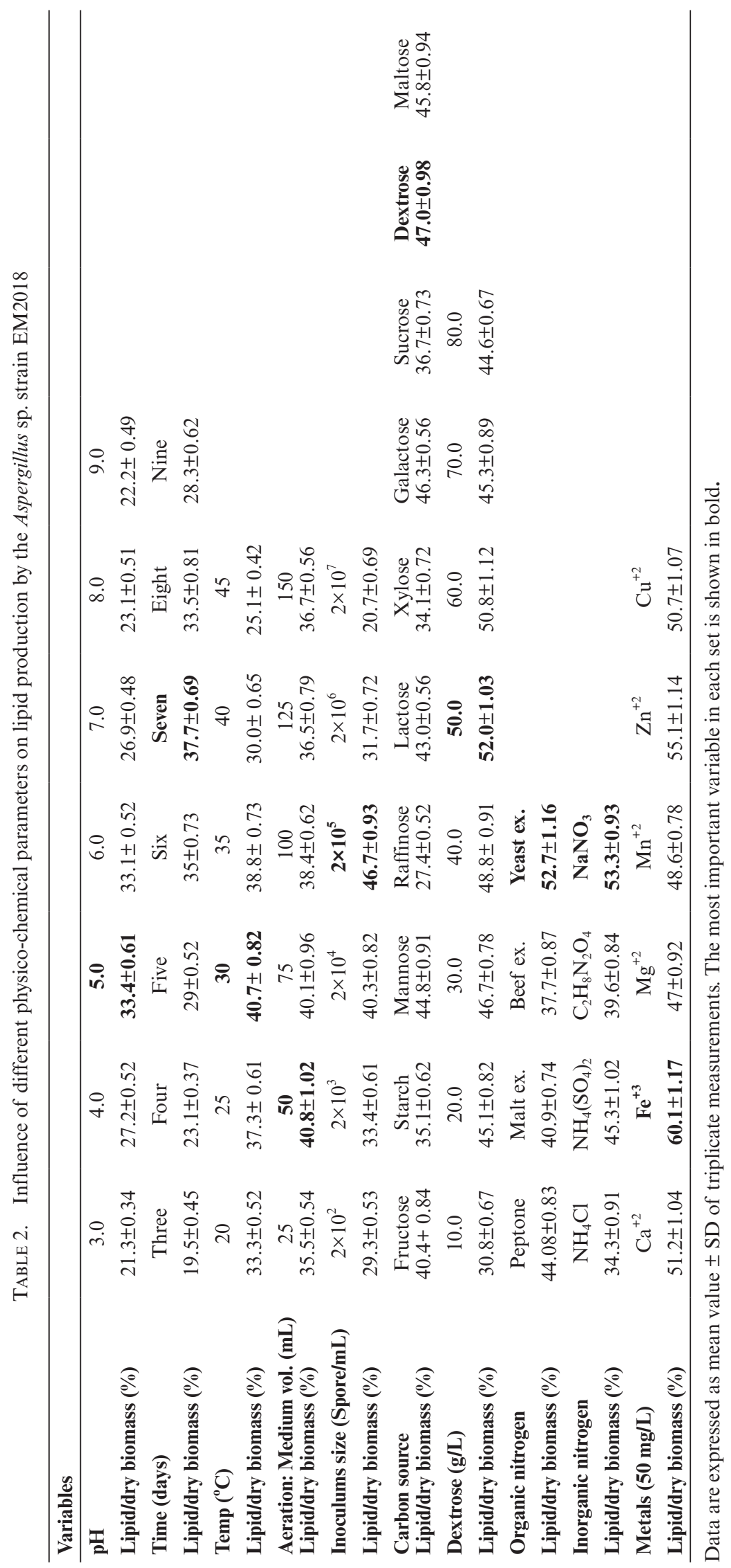


Under static condition, the amounts of sterol and phospholipids decreased while the glyceride fraction highly varied, which resulted in an increasing amount of saturated fatty acids (the main component of lipids). In this regard, Babij et al., (1969) and Valero et al., (2001) reported an increase in the amounts of linolenic acid and palmitoleic acid in the fatty acid profiles of Candida utilis and Saccharomyces cerevisiae, respectively, after the input of plenty of oxygen to the culture medium contents.

\subsubsection{Influence of inoculum size on lipid production by Aspergillus sp. strain EM2018}

The influence of various inoculum concentrations on lipid production by the Aspergillus sp. strain EM2018 was determined. The data revealed that the optimum lipid production of $7.3 \mathrm{~g} / \mathrm{L}(46.7 \%$ lipid/dry biomass) was obtained by using $2.0 \mathrm{~mL}$ of the spore suspension containing $2 \times 10^{5}$ spore $/ \mathrm{mL}$ after seven days of incubation in static conditions in the optimal medium (medium VII) as shown in Table 2. In addition, a reduction in fungal lipid accumulation was detected at lower or higher inoculum sizes than the optimum level. At higher inoculum size the inhibitory effect on lipid accumulation might be due to the depletion of the nutrients and oxygen available in the culture medium. While at lower inoculum size, the fugal biomass cannot proliferate quickly, leading to slow substrate degradation that subsequently influences lipid accumulation (Sethi et al., 2013).

\subsubsection{Effect of supplementary carbon and nitrogen sources on lipid production}

Sugars are the most effective energy sources when compared to other raw materials and are also easily assimilated by many oleaginous microorganisms. In this study, the data clearly revealed that dextrose was the best carbon source for maximum lipid accumulation (47.0\% lipid/dry biomass) and biomass formation followed by galactose and maltose which gave $46.3 \%$ and $45.8 \%$ lipid/dry biomass, respectively. On the other hand, the smallest amount of lipid accumulation was reported with raffinose and xylose $(27.4 \%$ and $34.1 \%$ lipid/dry biomass), respectively, as shown in Table 2 . These results are in agreement with Ali and El-Ghonemy (2014), who reported that the highest fungal biomass and lipid production by $T$. viride were obtained when dextrose was used as a sole source of carbon. While Hussein et al., (2017) reported that xylose followed by glucose were the best carbon sources for the growth and lipid accumulation of Penicillium commune NRC 2016. Venkata and Venkata (2011) reported that lipid accumulation in oleaginous fungi increased in the presence of excess carbon and a limited amount of nitrogen in the culture medium.
As dextrose was reported as the preferable carbon source for lipid production by the Aspergillus sp. strain EM2018, different concentrations of dextrose $(1-8 \%)$ were tested to determine its optimal concentration. The results revealed that the highest biomass formation and lipid accumulation (52.0\% lipid/dry biomass) were observed with the prepared PDL medium containing $50 \mathrm{~g} / \mathrm{L}$ of dextrose as shown in Table 2. In addition, lipid production by oleaginous fungi was directly proportional to the concentration of dextrose up to certain limits, after which a decline in lipid accumulation was detected. Similarly, Ali and El-Ghonemy (2014) reported that dextrose at a concentration of $50 \mathrm{~g} / \mathrm{L}$ gave the highest lipid production by Trichoderma viride NRC 314.

TAG synthesis is greatly affected by the carbon added to the culture medium. Initially, the fungus utilized the carbon in the culture medium for growth and cell maintenance, and then produced a biomass free from lipids, including functional lipids, after which the remained carbon was further utilized for lipid accumulation. In the presence of a sufficient amount of carbon, the rate of lipid production and accumulation was increased up to a maximum level. While in limited amount of carbon, the intracellular stored lipid was utilized to sustain cell generation and the formation of biomass free from lipids. High concentrations of glucose enhanced the carbon flow direction toward TAG production, thus improving lipid production. However, the utilization of high concentrations of sugar might have an inhibitory effect on microbial growth (Economou et al., 2011b).

A nitrogen source is also considered a limiting nutrient that plays a key role in lipid accumulation by microorganisms. In this work, the supplementation of additional nitrogen sources either organic or inorganic to the basal medium showed a profound effect on lipid production by the Aspergillus sp. strain EM2018. Among the organic nitrogen sources tested, the culture medium amended with yeast extract favored maximum biomass formation and lipid accumulation $(52.7 \%$ lipid/dry biomass) followed by peptone (44.0\%) and malt extract $(40.9 \%)$. This might be due to the enrichment of yeast extract with all the required metal ions and micronutrients (Dyal et al., 2005). The lowest lipid production of $37.7 \%$ lipid/dry biomass was reported with medium-containing beef extract. These results are in agreement with Abdelhamid (2018) who found that the highest lipid accumulation of $52.42 \%$ lipid/ dry biomass by Fusarium oxysporum NRC 2017 was reported in the presence of yeast extract. Likewise, Gao et al., (2013) reported optimal lipid production from Mortierella isabellina when yeast extract was used as a source of nitrogen.

The results also revealed that sodium nitrate was the best inorganic nitrogen supplement for a maximum fungal lipid production of $53.3 \%$ lipid/ 
dry biomass followed by ammonium sulphate (45.3\% lipid/dry biomass) and ammonium oxalate (39.6\% lipid/dry biomass); while the least production of lipids was observed with ammonium chloride medium (34.3\% lipid/dry biomass), as shown in Table 2. On the other hand, Venkata and Venkata (2014) reported an increase in lipid production from Aspergillus awamori when the concentration of nitrogen was decreased, while reaching its optimum when nitrogen was depleted. Gao et al., (2013) stated that nitrogen is an important factor for the flux regulation from carbon to lipids; whereas nitrogen metabolism products play a key role in altering the flux of carbon to the biosynthesis of lipid precursors.

\subsubsection{Effect of metal ions on lipid accumulation by the Aspergillus sp. strain EM2018}

Metal ions are considered important minor nutrients in the growth medium (medium VII) for biomass formation and lipid accumulation by microorganisms. In this study, the effect of the addition of different metal ions in the form of chloride salts on lipid production by the Aspergillus sp. strain EM2018 was evaluated in submerged culture fermentation. The results revealed that $\mathrm{Fe}^{+3}, \mathrm{Zn}^{+2}$ and $\mathrm{Ca}^{+2}$ had significant effects on lipid accumulation when compared to cultures without metal ions, which gave about 60.1, 55.1 and $51.2 \%$ lipid/dry biomass, respectively, as shown in Table 2 . These results are in agreement with Muhid et al., (2008) who reported that $\mathrm{Fe}^{+3}$ and $\mathrm{Zn}{ }^{+2}$ have a significant effect on the production of lipids by Cunninghamella $\mathrm{sp}$ $2 \mathrm{~A} 1$ as the inclusion of each metal ion resulted in 43 and $33 \%$ lipid/dry biomass, respectively.

The presence of metal ions in the culture medium may affect lipid production by affecting lipid biosynthesis pathways (Muhid et al., 2008). Shuib et al., (2014) reported that the addition of $\mathrm{Mg}^{+2}$, $\mathrm{Ca}^{+2}, \mathrm{Mn}^{+2}, \mathrm{Fe}^{+3}, \mathrm{Cu}^{+2}$ and $\mathrm{Zn}^{+2}$ enhanced the accumulation of $\gamma$-linolenic-acid-rich lipids by Cunninghamella bainieri 2A1; while the growth was not affected by the added metal ions due to the limited nitrogen content available in the medium.

\subsection{Effect of different extraction solvents}

The amount of total lipid yield from oleaginous microorganisms varies with the type of preliminary extracting organic solvents and the ratios of polar solvents to nonpolar solvents (Somashekar et al., 2001). In the present study, different solvents were tested to determine the effect of sample preparation on the assay. The results revealed that the color development was higher with chloroform: methanol (C: M) (2:1) in comparison to the other solvents, followed by hexane: acetone (1:1), while the least color developed was with the soxhlet extraction

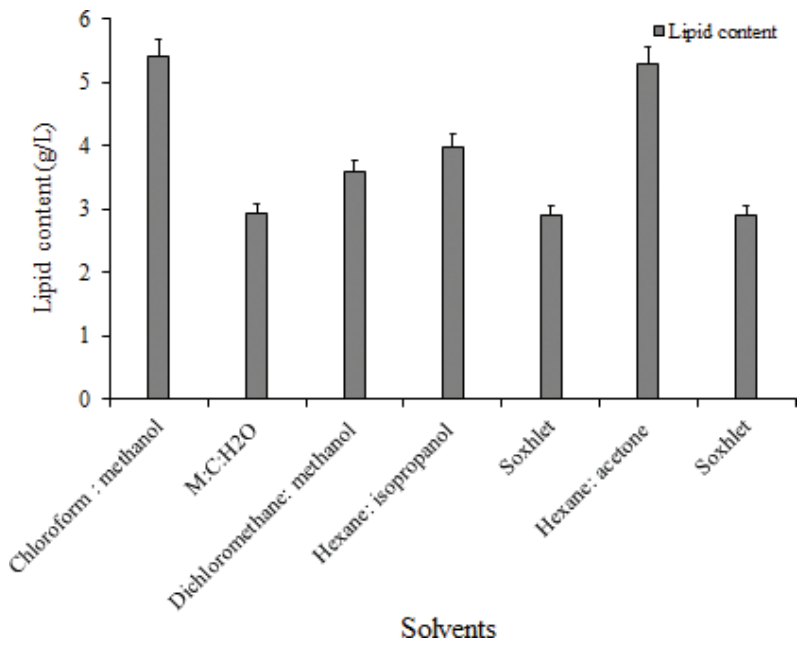

FIGURE 6. Effect of different extraction solvents on lipid production by the Aspergillus sp. strain EM2018 (at initial $\mathrm{pH}$ of 6 , incubation temperature at $30^{\circ} \mathrm{C}$ and 7 days of incubation in static conditions. Data are expressed as mean value of triplicate measurements and error bars denote the standard deviation).

technique as indicated in Fig. 6, which might be due to the poor lysis of cells during extraction because of the minimum contact between the cells and the solvent.

These results are in agreement with those of Somashekar et al., (2001), who found that, C: M (2:1) was the suitable solvent for optimal lipid extraction from Mucor rouxii. The Bligh and Dyer extraction method (C:M) was found to show the best performance in lipid yield among the six extraction methods tested because it was able to extract both the neutral and polar lipids from microbial biomass. However, its high solvent toxicity limits its commercial application (Halim et al., 2012). Somashekar et al., (2001) reported that the combination of polar and non-polar solvents was advantageous for lipid extraction from microorganisms, while hexane extraction (Soxhlet, hexane: isopropanol and hexane: acetone) and dichloromethan: methanol methods were less toxic but with low efficiency for lipid extraction.

\subsection{Fatty acid profile of Aspergillus sp. strain EM2018 SCO using GC}

In the present investigation, the optimized oil of the Aspergillus sp. strain EM2018 was transesterified to FAME and analyzed with GC and the profile obtained is shown in Table 3. The fungal fatty acid profile demonstrates that it is composed of high percentages of mono- and poly unsaturated fatty acids, 24.43\% C18:2 (Linoleic acid), 14.09\% C18:1 (Oleic acid), 7.44\% C20:4 (Arachidonic acid), 1.38\% C16:1 (Palmetoleic acid) and 1.1\% C18:3 (Linolenic acid), and a limited percentage of saturated fatty 
TABLE 3 Lipid profile of a new terrestrial fungus Aspergillus sp. strain EM2018 and its fatty acid percentage (Gas chromatographic analysis)

\begin{tabular}{lcclc}
\hline Peak No & Carbon No & RT & Scientific name & Percentage (\%) \\
\hline 1 & C12(0) & $12.1 \pm 0.31$ & Lauric acid & $0.4 \pm 0.05$ \\
2 & C14(0) & $13.4 \pm 0.24$ & Myristic acid & $0.5 \pm 0.07$ \\
3 & C16(0) & $14.9 \pm 0.18$ & Palmitic acid & $33.3 \pm 1.41$ \\
5 & C16(1) & $15.5 \pm 0.45$ & Palmitoleic acid & $1.4 \pm 0.02$ \\
7 & $\mathrm{C} 18(0)$ & $16.4 \pm 0.32$ & Stearic acid & $0.7 \pm 0.04$ \\
9 & $\mathrm{C} 18(1)$ & $17.6 \pm 0.51$ & Oleic acid & $14.1 \pm 0.56$ \\
11 & $\mathrm{C} 18(2)$ & $18.9 \pm 0.39$ & Linoleic acid & $24.4 \pm 0.34$ \\
12 & $\mathrm{C} 18(3)$ & $20.8 \pm 0.57$ & Linolenic acid & $1.1 \pm 0.04$ \\
13 & $\mathrm{C} 20(4)$ & $23.8 \pm 0.81$ & Arachidonic acid & $7.4 \pm 0.06$ \\
14 & $\mathrm{C} 22(0)$ & $24.8 \pm 0.58$ & Behenic acid & $1.5 \pm 0.02$ \\
15 & $\mathrm{C} 24(0)$ & $26.1 \pm 0.37$ & Lignoceric acid & $15.2 \pm 0.47$ \\
\hline
\end{tabular}

Data are expressed as mean value \pm SD of triplicate measurements.

acids, 33.33\% C16:0 (Palmitic acid), 15.1\% C24:0 (Lignoceric acid), $1.478 \% \mathrm{C} 22: 0$ (Behenic acid), 0.68\% C18:0 (Stearic acid), 0.449\% C14:0 (Myristic acid) and $0.438 \% \mathrm{C} 12: 0$ (Lauric acid).

This result is relatively close to that reported for the fatty acid profile of $A$. awamori lipids, although it differs in the ratio of saturated to unsaturated fatty acids, as reported by Venkata and Venkata (2011). Ali and El-Ghonemy (2014) reported a large amount of palmitoleic acid (C16:0), linoleic acid (C18:2) and linolenic acid (C18:3) up to 30, 23 and $13 \%$, respectively, in T. viride NRC 314 biomass. Halim et al., (2012) reported that the fatty acid profile of microalgae mainly composed of linoleic (C18:2), oleic (C18:1), linolenic (C18:3) and palmitoleic (C16:1) with trace amounts of saturated fatty acids, such as palmitic (C16:0) and stearic (C18:0).

In addition, the data reported showed that Aspergillus sp. strain EM2018 SCO differed from that of vegetable oils in that it is rich in PUFAs. In addition, the presence of arachidonic acid in a considerable amount (7.44\%) makes this oil suitable for human use (edible). Arachidonic acid plays an important role in slowing the progress of alzheimer disease, in treating arthritis and in increasing muscle mass and overcoming depression. Recently, new studies have been focused on polyunsaturated fatty acids (PUFAs) such as arachidonic acid and linolenic acid because of their biotechnological applications (Sakuradani et al., 2009). PUFAs are used for infant nutrition and as dietary supplements. For biodiesel preparation, several researchers have supported the idea of utilizing filamentous fungi due to their rapid growth, lack of a need for light energy, easy scalability and ability to use various renewable substrates. Palmitic acid (C16:0), stearic acid (C18:0) and oleic acid (C18:1) are considered potential targets of interest due to their properties of higher value oils, improved oxidative stability and potential adaptability in biodiesel production (Economou et al., 2011a).

\section{CONCLUSIONS}

Fifty fungal species were locally isolated and screened for their lipid production. A new fungus identified genetically as the Aspergillus sp. strain EM2018 was reported as the most promising strain for lipid accumulation $(25.2 \%)$ with essential PUFAs. The optimization of cultural and nutritional conditions enhanced lipid production from 25.2 to $60.1 \%$ by the fungus grown in the PDL medium, with initial $\mathrm{pH}$ of 5.0 , for seven days at $30^{\circ} \mathrm{C}$ under static conditions and inoculums size of $2 \mathrm{~mL}\left(2 \times 10^{6}\right.$ spore $\left./ \mathrm{mL}\right)$. The gas chromatography analysis of Aspergillus sp. strain EM2018 lipid revealed that it consists of saturated fatty acids (such as palmitic acid and lignoceric acid) and momo and poly-unsaturated FAs (such as linoleic acid, oleic acid and arachidonic acid). In addition, the fungal SCO contains arachidonic acid in a considerable amount, about $7.44 \%$, which plays an important role in overcoming depression, treating arthritis, slowing the progress of alzheimer disease and increasing muscle mass.

\section{ACKNOWLEDGEMENTS}

The authors are thankful to the National Research Center (NRC), Egypt, for the facilities that enabled them to accomplish this work.

\section{CONFLICT OF INTERESTS}

The authors declared no conflict of interest. 


\section{REFERENCES}

Abdelhamid SA. 2018. Biochemical studies on the production of biodiesel from some species of fungi. Master of Science, Ain Shams University.

Ageitos JM, Vallejo JA, Veiga-Crespo P, Villa TG. 2011. Oily yeasts as oleaginous cell factories. Appl. Microbiol. Biotechnol. 90, 1219-1227. https://doi.org/10.1007/s00253-011-3200-z

Ali TH, El-Ghonemy DH. 2014. Optimization of culture conditions for the highest lipid production from some oleaginous fungi for biodiesel production. Asian J. Appl. Sci. 2 (5), 600-609.

Ali TH, El-Gamal MS, El-Ghonemy DH, Awad GE, Tantawy AE. 2017. Improvement of lipid production from an oil- producing filamentous fungus, Penicillium brevicompactum NRC 829 through central composite statistical design. Ann. Microbiol. 67, 601-613. https://doi. org/10.1007/s13213-017-1287-x

Association of Official Analytical Chemists (AOAC). 2000. Official method 971.24. Aflatoxins in coconut, copra, and copra meal. Rockville, MD, USA: AOAC international.

Azócar L, Ciudad G, Heipieper HJ, Navia R. 2010. Biotechnological processes for biodiesel production using alternative oils. Appl. Microbiol. Biotechnol. 88 (3), 621-636. https://doi.org/10.1007/s00253-010-2804-z

Babij T, Moss FJ, Ralph BJ. 1969. Effect of oxygen and glucose levels on lipid composition of yeast Candida utilis grown on continous culture. Biotechnol. Bioeng. 11, 593-603. https://doi.org/10.1002/bit.260110407

Chen XF, Huang C, Xiong L, Chen X, Chen Y, Maa LL. 2012. Oil production on wastewaters after butanol fermentation by oleaginous yeast Trichosporon coremiiforme. Bioresour. Technol. 118, 594-597. https://doi.org/10.1016/j. biortech.2012.05.023

Chuppa-Tostain G, Hoarau J, Watson M, Adelard L, Cheong Sing A, Caro Y, Grondin I, Bourven I, Francois J, Girbal-Neuhauser E, Petit T. 2018. Production of Aspergillus niger biomass on sugarcane distillery wastewater: physiological aspects and potential for biodiesel production. Fungal Biol. Biotechnol. 5, 1-12. https://doi. org/10.1186/s40694-018-0045-6

Devi P, D'souza L, Kamat T, Rodrigues C, Naik CG. 2009. Batch culture fermentation of Penicillium chrysogenum and a report on the isolation, purification, identification and antibiotic activity of citrinin. Indian J. Mar. Sci. 38, 38-44.

Dyal SD, Bouzidi L, Narine SS. 2005. Maximizing the production of $\gamma$-linolenic acid in Mortierella ramanniana var. ramanniana as a function of $\mathrm{pH}$, temperature and carbon source, nitrogen source, metal ions and oil supplementation. Food Res. Int. 38 (7), 815-829. https://doi. org/10.1016/j.foodres.2005.04.002

Economou CN, Aggelis G, Pavlou S, Vayenas DV. 2011a. Modelling of single cell oil production under nitrogen limited and substrate inhibition conditions. Biotechnol. Bioeng. 108, 1049-1055. https://doi.org/10.1002/bit.23026

Economou CN, Aggelis G, Pavlou S, Vayenas DV. 2011b. Single cell oil production from rice hulls hydrolysate. Bioresour. Technol. 102 (20), 9737-9742. https://doi.org/10.1016/j. biortech.2011.08.025

Gao D, Zeng J, Zheng Y, Yu X, Chen S. 2013. Microbial lipid production from xylose by Mortierella isabellina. Bioresour. Technol. 133, 315-321. https://doi.org/10.1016/j. biortech.2013.01.132

Ghaly AE, Dave D, Brooks MS, Budge S. 2010. Production of biodiesel by enzymatic Transestrification: Review. Am. J. Biochem. Biotechnol. 6 (2), 54-76. https://doi.org/10.3844/ ajbbsp.2010.54.76

Halim R, Danquah MK, Webley PA. 2012. Extraction of oil from microalgae for biodiesel production: a review. Biotechnol. Adv. 30 (3), 709-732. https://doi.org/10.1016/j. biotechadv.2012.01.001

Hussein AA, El Sayed OH, Asker MS, Mohamed, SS, Abdelhamid SA. 2017. Biodiesel production from local isolate Penicillium commune NRC 2016. J. Sci. Res. Sci. 34, 179-193. https://doi.org/10.21608/JSRS.2018.12970
Inouye LS, Lotufo GR. 2006. Comparison of macrogravimetric and micro-colorimetric lipid determination methods. Talanta 70 (3), 584-587.

Kirrolia A, Bishnoi NR, Singh R. 2013. Microalgae as a boon for sustainable energy production and its future research and development aspects. Renew. Sust. Energ. Rev. 20, 642-656. https://doi.org/10.1016/j.rser.2012.12.003

Kumar SP, Banerjee R. 2013. Optimization of lipid enriched biomass production from oleaginous fungus using response surface methodology. Indian J. Exp. Biol. 51 (11), 979-983.

Mamatha S, Ravi R, Venkateswaran G. 2008. Medium optimization of gamma linolenic acid production in Mucor rouxii CFR-G15 using RSM. Food Bioprocess. Tech. 1 (4), 405-409. https://doi.org/10.1007/s11947-008-0103-9

Mishra SK, Suh WI, Farooq W, Moon M, Shrivastav A, Park MS, Ji-Won Y. 2014. Rapid quantification of microalgal lipids in aqueous medium by a simple colorimetric method. Bioresour. Technol. 155, 330-333. https://doi.org/10.1016/j. biortech.2013.12.077

Muhid F, Nawi WNNW, Abdul Kader AJ, Yusoff WMW, Abdul Hamid A. 2008. Effects of metal ion concentrations on lipid and gamma linolenic acid production by Cunninghamella sp 2A1. Online J. Biol. Sci. 8 (3), 62-67.

Ruan Z, Zanotti M, Zhong Y, Liao W, Ducey C, Liu Y. 2013. Co-hydrolysis of lignocellulosic biomass for microbial lipid accumulation. Biotechnol. Bioeng. 110 (4), 1039-1049. https://doi.org/10.1002/bit.24773

Sakuradani E, Ando A, Ogawa J, Shimizu S. 2009. Improved production of various polyunsaturated fatty acids through filamentous fungus Mortierella alpine breeding. Appl. Microbiol. Biotchnol. 84 (1), 1-10. https://doi.org/10.1007/ s00253-009-2076-7

Sethi BK, Rout JR, Das R, Nanda PK, Sahoo SL. 2013. Lipase production by Aspergillus terreus using mustard seed oil cake as a carbon source. Ann. Microbiol. 63 (1), 241-252. https://doi.org/10.1007/s13213-012-0467-y

Shuib S, Nawi WN, Taha EM, Omar O, Kader AJ, Kalil MS, Hamid AA. 2014. Strategic feeding of ammonium and metal ions for enhanced GLA-rich lipid accumulation in Cunninghamella bainieri 2A1. Scientific World J. 2014, 1-8. https://doi.org/10.1155/2014/173574

Tamura K, Dudley J, Nei M, Kumar S. 2007. MEGA4: molecular evolutionary genetics analysis (MEGA) software version 4.0. Mol. Biol. Evol. 24, 1596-1599. https://doi. org $/ 10.1093 / \mathrm{molbev} / \mathrm{msm} 092$

Umesha S, Manukumar HM, Raghava S. 2016. A rapid method for isolation of genomic DNA from food-borne fungal pathogens. 3 Biotech. 6 (2), 123-128. https://doi. org/10.1007/s13205-016-0436-4

Valero E, Millan C, Ortega JM. 2001. Influence of oxygen addition during growth phase on the biosynthesis of lipids in Saccharomyces cerevisiae (M (3)30-9) in enological fermentations. J. Biosci. Bioeng. 92 (1), 33-38. https://doi. org/10.1016/S1389-1723(01)80195-X

Venkata Subhash G, Venkata Mohan S. 2011. Biodiesel production from isolated oleaginous fungi Aspergillus sp. using corncob waste liquor as a substrate. Bioresour. Technol. 102, 9286-9290. https://doi.org/10.1016/j. biortech.2011.06.084

Venkata Subhash G, Venkata Mohan S. 2014. Lipid accumulation for biodiesel production by oleaginous fungus Aspergillus awamori: Influence of critical factors. Fuel 116, 509-515. https://doi.org/10.1016/j.fuel.2013.08.035

Vicente G, Bautista LF, Rodríguez R, Gutiérrez FJ, Martinez V, Rodríguez Frometa RA, Ruiz-Vazquez RM, TorresMartinez S, Garre V. 2010. Direct transformation of fungal biomass from submerged cultures into biodiesel. Energy Fuels 24, 3173-3178. https://doi.org/10.1021/ef9015872

Yehia RS, Ali EM, Al-Zahrani A. 2017. Feasibility of oleaginous fungi isolated from soil samples of Saudi Arabia for Mycodiesel production. Appl. Biochem. Microbiol. 53 (1), 94-100. https://doi.org/10.1134/S0003683817010045

Zhao X, Hu C, Wu S, Shen H, Zhao ZK. 2011. Lipid production by Rhodosporium toruloides Y4 using different substrate feeding strategies. J. Ind. Microbiol. Biotechnol. 38 (5), 627-632. https://doi.org/10.1007/s10295-010-0808-4 